\title{
A plea for an experimental philosophy of medicine
}

\author{
Andreas De Block ${ }^{1}$ (D) Kristien Hens ${ }^{1,2}$ (D) \\ Accepted: 17 November 2021 / Published online: 17 December 2021 \\ (c) The Author(s), under exclusive licence to Springer Nature B.V. 2021
}

This special issue aims to explore and investigate a new subfield, namely experimental philosophy of medicine. Whereas experimental philosophy is relatively new on the philosophical block, some of its takes and findings have already shaped central debates in ethics, philosophy of action, philosophy of language, and epistemology. Interestingly, the approach of this program was for a long time almost wholly ignored within bioethics and philosophy of medicine-although this seems to have changed somewhat recently. In this introduction, we briefly sketch the program of experimental philosophy and how it can be used to shed philosophical light on issues in the philosophy of medicine.

\section{From philosophy to experimental philosophy}

Experimental philosophy applies tools and methods from the social sciences to examine philosophical issues and problems. These tools and methods include, but are certainly not limited to, quantitative and qualitative analyses of data from observational studies, laboratory experiments, and archives. Critics have understood this approach as part of what Peter Simons has called a brave new world model of philosophy, a model that prides itself in being a new method that will give us 'a completely new access to philosophical truth in a way which has never been given before' [1, p. 72]. We think this conception of experimental philosophy is incorrect. Instead, experimental philosophy is continuous with how philosophy has been done since its inception. In the distant and not so distant past, philosophers have tried to answer questions that are now generally considered to fall within the purview of science. Aristotle, René Descartes, and John Locke have all inquired into issues and topics that are currently dealt with in physics, biology, and psychology. Relatedly,

Andreas De Block

andreas.deblock@kuleuven.be

Kristien Hens

kristien.hens@uantwerpen.be

1 Centre for Logic and Philosophy of Science, Institute of Philosophy, KU Leuven, Leuven, Belgium

2 Department of Philosophy, University of Antwerp, Antwerp, Belgium 
many of the founding fathers of the natural and social sciences self-identified as philosophers. Some even thought of themselves as experimental philosophers-think Robert Boyle, Isaac Newton, Wilhelm Wundt, and the like. To this day, the University of Oxford still has a professorship in experimental philosophy, a position that is occupied by what people outside of Oxford would simply call a physicist. Even in the nineteenth and twentieth century, sciences such as linguistics, computer science, and psychology were born out of philosophy's womb.

Of course, one could say that what is left of philosophy today is genuine philosophy or that the current problems of philosophy are what philosophy should have always been about. From that perspective, philosophers should be happy to have parted ways with the sciences and to have finally discovered the essence of their field. Again, we think such a view is mistaken. First, essentialism about academic disciplines seems to be naïve and, frankly, unphilosophical. As Stephen Turner puts it, "essentialism about disciplines—claims about what "really" is or is not a part of discipline, or about how the intellectual universe would be divided up if it were cut at the joints-is invariably bad history' [2, p. 55]. Second, this view likely suffers from a kind of survivorship bias. The topics that are now studied in the social, life, and natural sciences are often no less philosophical than what current philosophy focuses on. Rather, definitions of philosophy co-evolve with what those who identify (or are identified) as philosophers engage in. Ultimately, such an essentialist vision of philosophy can lead to gatekeeping. It can have negative consequences for those philosophers who do venture outside of what is considered genuine philosophy, as funders and employers may look negatively on their work. In this respect, the experimental philosopher is confronted with obstacles similar to those by scholars in other cross-disciplinary endeavours.

Proponents of experimental philosophy, on their end, emphasise the continuity between philosophy and the sciences. According to them, philosophers are in rough proximity to the sciences and can therefore deploy the same methodologies. Indeed, many philosophers, those outside experimental philosophy included, subscribe to the naturalistic view that one should generally avoid contradicting the most robust scientific findings. If philosophical conclusions violate what evolutionary biology says about natural selection or if they are at odds with the second law of thermodynamics, then philosophers sure have a good deal of explaining to do. Philosophers accept this relatively toothless naturalism because they believe that the best scientific knowledge is highly informative about how the world is and how our minds work. Since science is 'an enormously successful epistemic enterprise that teaches us about how the world is' [3, p. 4], philosophical analyses and arguments that seek to explore how the world is should take account of what science (or the sciences) has to teach.

If science and philosophy both aim at an accurate understanding of the world and human beings, then it seems reasonable to go one step further. Why should philosophical toolkits not also include scientific methods, if such methods have proven successful in the sciences? Obviously, the philosophical application of scientific methods makes sense only if these methods can help to bring philosophical issues into focus. We think previous studies in experimental philosophy have made clear that this is possible, demonstrating that experimental philosophy can 
be a fruitful research program in philosophy. For example, at the beginning of this century, Joshua Knobe used experimental methods to show that people's intuitions about whether side-effects can be brought about intentionally differ depending on whether the side-effects are beneficial or harmful [4]. Knobe's finding has had a lasting influence on the philosophical literature around moral responsibility [5], intentionality [6], and even several debates in epistemology [7]. Similarly, around the same time that Knobe conducted his study, Edouard Machery and colleagues researched whether intuitions about reference differ across cultures [8]. The results of their vignette study suggest that Westerners tend to have intuitions about the reference of proper names that fit the causal-historical (Kripkean) view, whereas East Asians tend to have intuitions consistent with the descriptivist (Fregean) view. Again, this finding has spurred debates in several philosophical subdisciplines, including, inter alia, philosophy of language [9] and the philosophy of race [10].

\section{From experimental philosophy of science to experimental philosophy of medicine}

Experimental philosophy, including experimental philosophy of science, has established itself as a way of doing philosophy. It is discussed and practised by leading philosophers, is the subject of regularly organised philosophical conferences and workshops, and has led to numerous high-profile publications; it even has its own book series with prestigious academic publishers $[11,12]$. Still, experimental philosophy of medicine seems not to have gotten off the ground, despite philosophers' having already hinted repeatedly at how the experimental approach could present a promising new direction for philosophy of medicine (see [13]). Its failure to launch is all the more surprising given the naturalistic inclinations of many outspoken philosophers of medicine, as well as their general willingness to set up interdisciplinary collaborations with scientists, including those whose research is primarily experimental. Moreover, much of mainstream bioethics, its cousin discipline, is empirical and is based on interviews or surveys.

Of course, some experimental philosophy of science-experimental philosophy of biology in particular-is highly relevant for philosophy of medicine. For instance, the empirical study of how laypeople and scientists conceive of innateness and naturalness bears on issues such as constructivism in philosophy of psychiatry [14]. Likewise, philosophical analyses of the gene concept in the biomedical sciences should take into account the results of a systematic study into how researchers in different biological subfields conceive of genes $[15,16]$. Nevertheless, the numerous implications of such experimental or otherwise empirical research into these concepts and the work they do in science have rarely been discussed or addressed in journals devoted to philosophy of medicine or bioethics-let alone used as a starting point for experimental philosophy of medicine. By the same token, it is curious that so few of the intuitions underlying claims in the philosophy of medicine literature have been systematically scrutinised using social scientific methods given that philosophers routinely make use of the 'method of cases' - by which actual cases or thought experiments are used to elicit everyday judgments thought to serve an 
evidential role in philosophical arguments [17]. If cases are being used to elicit judgments, it seems only natural to look systematically at the judgments elicited. Instead, philosophers all too often assume that their elicited judgments-for instance, that 'old age is not a disorder', to paraphrase Christopher Boorse [18]; or that 'the life of a handicapped child is less worth living than the life of an able-bodied child', as implied in Derek Parfit's famous thought experiment illustrating the non-identity problem [19] — are the same as those of other people, or at least similar enough to other philosophers' judgments for them to play their evidential role.

Moreover, given the nature of medicine itself, primarily a praxis rather than a theory, it seems even more relevant to investigate whether the intuitions resulting from cases and the conclusions drawn from them actually do serve some evidential role. It is sometimes presumed that the intuitions of trained philosophers have some privileged pathway to the truth, and therefore experiments demonstrating that laypeople might have different intuitions do not present fatal evidence against the conclusions drawn from them by philosophers [20]. However, even more so than in epistemology or philosophy of language, in philosophy of medicine this so-called expertise defence seems unconvincing [21] (cf. [22] for a qualified version of the defence). After all, when investigating concepts of health, disease, disability, wellbeing, or the like, it is unclear why the intuitions of philosophers would count more than the intuitions of, say, medical doctors or those who have a specific condition or disability. Indeed, disability activists and scholars have challenged the idea often taken for granted in philosophy that life with a disability is less worth living than able-bodied life [23]. Furthermore, the necessary conditions for calling something health or disease may vary across languages and cultures. Experimental philosophy can surely help to illuminate similarities and contrasts in the intuitions and opinions of different linguistic and cultural groups [24, 25].

Precisely given the particularistic nature of medicine, experimental philosophy of medicine could go beyond the traditional method of using vignette surveys to elicit judgments, as is common practice in experimental philosophy. Up until now, experimental philosophers have primarily conducted quantitative research using surveys, though some have also used techniques like brain imaging (e.g., [26]). Assuming a broad definition of experimental philosophy as the application of empirical methods to answer philosophical questions, the project of experimental philosophers can benefit from engagement with a more diverse range of empirical tools. Recently, experimental philosophers have employed corpus analytic techniques to investigate the evolution of concepts in common usage or within specific disciplines [27]. Experimental philosophers of medicine could deploy such methods to investigate whether the concept of disease has changed over time, for example, by examining diachronic variation in the lexical items that collocate with disease within a specialised corpus of academic texts. Moreover, in empirical bioethics, there is a decades-long tradition of using qualitative methods like interviews and focus groups [28] - methods that could also have valuable applications in experimental philosophy of medicine. Qualitative research can help to query the underlying assumptions and values at play in the results of quantitative studies; it can also provide new insights that are worthy of philosophical exploration and serve as inspiration for new quantitative studies. Besides interviews and focus groups, disability scholars have employed art-based 
methods to probe the experiences of individuals who do not speak (see, e.g., [29]). If it is the case, as we assume, that the input of those who have been ignored by traditional empirical approaches is important for philosophy of medicine, to the extent that medicine often involves them, an alliance between experimental philosophy of medicine and disability studies may open up new ways of doing empirical research. Additionally, the idea that insights from medical anthropology or science and technology studies could avail philosophers of medicine has gained more ground over the last few decades; in that event, the methodologies used in those fields, such as ethnography, could be taken up by philosophers as well.

All this is not to say that there have been no earlier attempts at doing experimental philosophy of medicine [30]. For instance, Jerome Wakefield has worked with social scientists to test whether his philosophical analysis of disorder as a harmful dysfunction is able to predict the judgment of clinicians, finding some evidence for the validity of his account [31]. Furthermore, as we already mentioned, some empirical work in bioethics and medical ethics comes close to what might be called experimental philosophical bioethics [32]. Recently, Brian Earp started an experimental bioethics blog and co-organised the first experimental bioethics summit in 2019 at Yale University [33]. Similarly, the Association for the Advancement of Philosophy and Psychiatry chose 'Intuitions Meet Experiments: Methods in Philosophy of Psychiatry' as the theme for its annual conference in 2020 and asked Edouard Machery, a prominent proponent of experimental philosophy, to give the keynote address [34]. We think that this special issue can further help the field to catch up to the empirical philosophical bandwagon.

\section{Imagining experimental philosophy of medicine}

Rather than speculate about why experimental philosophy of medicine is still almost non-existent, we consider it more fruitful to reflect on its promises and limitations and how these are echoed and treated in this special issue. One of the co-editors of this issue, Kristien Hens, received a grant from the European Research Council (ERC Starting Grant) to do, among other things, experimental research on conceptual issues in philosophy of medicine. The successful proposal included a plan for an edited volume and a special issue on experimental philosophy of medicine. Hence a call for papers was launched in February 2020, after which the editors selected the most promising abstracts. The final selection of articles was based on two rounds of (double-blind) review by two peers.

The special issue has two foci. First, it aims to explore what experimental philosophy of medicine is and can be, and asks whether philosophy of medicine should welcome this novel approach. Are there good reasons to expect that empirically scrutinising the intuitions about and use of concepts underlying claims in philosophy of medicine will add to our philosophical knowledge? Experimental work in other philosophical (sub)disciplines suggests that this is the case. Second, it aims to illustrate how timely issues in the philosophy of medicine can be addressed using a variety of experimental methods. 
Examples of the promises of experimental philosophy of medicine can be found in four of the five contributions to the special issue [35-38]. These articles highlight the diversity of approaches (and their strengths) that can fare under the flag of experimental philosophy, some of which are empirical but not experimental in the strict sense. They also speak to the differences and similarities between experimental philosophy of medicine and other types of naturalistic philosophy of medicine where philosophers rely on scientific results but do not actively or systematically produce such results.

Yet it is also clear that this approach is not a panacea, as Anna Smajdor's contribution to this special issue underscores [39]. The so-called negative program of experimental philosophy has been much more successful than the positive program. In other words, the results of experimental philosophy have been successful in indicating severe problems with the traditional methods of appealing to intuitions as evidence for philosophical claims, and not so much in offering positive contributions to (variants of) these methods [41]. Furthermore, issues concerning the replicability and generalisability of findings in social sciences have had repercussions for experimental philosophy as a whole [42]. Still, the replicability of study results in experimental philosophy has proven to be relatively high [43], and as far as generalisability concerns, many studies in experimental philosophy have been conducted precisely to address this problem in philosophy by investigating variation across cultures and between different groups, rather than seeking a universal truth about a given phenomenon. As mentioned above, investigating such cross-cultural differences and similarities may even be more relevant in experimental philosophy of medicine. Another reason for moderate scepticism regarding experimental philosophy and its results has to do with the training and background of many experimental philosophers. Philosophical education is usually not focused on the social science methods experimental philosophers employ in their studies. A lack of understanding of these methods and a lack of attention to methodological details can render a study worthless. Thus, methodological scrutiny is a requirement in experimental philosophical studies.

Relatedly, we believe that before engaging in such a study, the relevance of the research question to existing philosophical debates or positions should be made very clear if the study's findings are to have an impact on the field. In this issue, the contribution by Walter Veit describes a way in which experimental methods can advance the debate between naturalists and normativists on the concepts of health and disease, a debate that has dominated the field of philosophy of medicine for decades [38]. Apart from investigating claims about medical concepts, experimental philosophy can also contribute to answering normative questions in medicine. In their contribution 'Experimental Philosophical Bioethics and Normative Inference', Brian Earp, Jonathan Lewis, and colleagues use case studies to investigate four approaches by which empirical data can be used to draw normative conclusions and hence supplement experimental bioethics' parent disciplines, empirical bioethics and experimental philosophy [35]. However, not all of the contributors to this issue convey the same enthusiasm for experimental philosophy and the insights it can offer. In her paper 'Why Bother the Public? A Critique of Leslie Cannold's Empirical Research on Ectogenesis', Anna Smajdor critically revisits a 1995 
paper by Cannold, challenging her claim that the results of her focus group study on ectogenesis and abortion demonstrate that philosophers are out of touch with how real women think about these issues [39] (cf. [40]). She argues that differences between the intuitions of laypeople and the arguments of trained philosophers are not surprising given that raw intuition and moral reasoning are distinct (and incomparable) phenomena, so the presence of such differences is not in itself a reason to doubt philosophers' conclusions.

This issue also includes two examples that offer an impression of how vexing and timely issues in the philosophy of medicine might be addressed using empirical methods. In their study 'Pain Priors, Polyeidism, and Predictive Power: A Preliminary Investigation into Individual Differences in Ordinary Thought about Pain', Emma Borg and colleagues report the findings of a survey study investigating whether there are individual differences in people's tendencies to conceive of pain as primarily a mental or a bodily phenomenon, a topic that is widely discussed in the philosophical literature [36]. They state that understanding these differences is not only of interest for the philosophical debate, but also has clinical relevance, as patients' inclinations to think about pain in mind-centric or body-centric ways may influence which treatments are effective. Their paper demonstrates how medical science is related to individual experiences and contexts and how acknowledging this relation is relevant also for philosophy.

Nevertheless, medical science is not immune to hype and unrealistic hopes. We can think about the promise of genetic medicine around the turn of the century, promise that has in no small measure failed to materialise. Corpus methods may prove to be an excellent way of tracking the rise and fall of such ideas and trends in medical science. In their paper 'Transposon Dynamics and the Epigenetic Switch Hypothesis', Stefan Linquist and Brady Fullerton examine a large sample of scientific publications in four disciplines (general biology, biomedicine, proximal biology, and evolution) and compare the prevalence of two alternative explanations for adaptive responses in organisms: epigenetic inheritance on the one hand and coevolutionary dynamics between transposons and host genome on the other [37]. They found that interest in epigenetic explanations is often inversely related to interest in transposons, suggesting that enthusiasm for specific types of explanation may give rise to a disciplinary myopia such that scientists are less likely to consider alternative explanations for observed phenomena.

Ultimately, we are confident that the papers in this special issue can together contribute to the maturation and impact of experimental philosophy of medicine.

Funding Andreas De Block and Kristien Hens have received funding from the European Research Council (ERC) under the European Union's Horizon 2020 research and innovation programme (grant agreement No 804881).

\section{References}

1. Simons, Peter. 2000. The four phases of philosophy: Brentano's theory and Austria's history. The Monist 83: 68-88. 
2. Turner, Stephen. 2000. What are disciplines? And how is interdisciplinarity different. In Practising interdisciplinarity, ed. Nico Stehr and Peter Weingart, 46-65. Toronto: University of Toronto Press.

3. Mallon, Ron. 2016. The construction of human kinds. Oxford: Oxford University Press.

4. Knobe, Joshua. 2003. Intentional action and side effects in ordinary language. Analysis 63: 190-194.

5. Nichols, Shaun, and Joshua Knobe. 2007. Moral responsibility and determinism: The cognitive science of folk intuitions. Noûs 41: 663-685.

6. Machery, Edouard. 2008. The folk concept of intentional action: Philosophical and experimental issues. Mind and Language 23: 165-189.

7. Beebe, James R., and Wesley Buckwalter. 2010. The epistemic side-effect effect. Mind and Language 25: 474-498.

8. Machery, Edouard, Ron Mallon, Shaun Nichols, and Stephen P. Stich. 2004. Semantics, cross-cultural style. Cognition 92: B1-B12.

9. Devitt, Michael. 2011. Experimental semantics. Philosophy and Phenomenological Research 82: 418-435.

10. Glasgow, Joshua. 2008. On the methodology of the race debate: Conceptual analysis and racial discourse. Philosophy and Phenomenological Research 76: 333-358.

11. Lombrozo, Tania, Joshua Knobe, and Shaun Nichols (eds.). 2015-22. Oxford studies in experimental philosophy. 4 vols. Oxford: Oxford University Press.

12. Beebe, James R. (ed.). 2014-22. Advances in experimental philosophy. 12 vols. London: Bloomsbury.

13. Lemoine, Maël, Marie Darrason, and Hélène Richard. 2014. Where is philosophy of medicine headed? A report of the International Advanced Seminar in the Philosophy of Medicine (IASPM). Journal of Evaluation in Clinical Practice 20: 991-993.

14. Griffiths, Paul, Edouard Machery, and Stefan Linquist. 2009. The vernacular concept of innateness. Mind and Language 24: 605-630.

15. Stotz, Karola, Paul E. Griffiths, and Rob Knight. 2004. How biologists conceptualize genes: An empirical study. Studies in History and Philosophy of Science Part C 35: 647-673.

16. Griffiths, Paul E., and Karola Stotz. 2006. Genes in the postgenomic era. Theoretical Medicine and Bioethics 27: 499-521.

17. Machery, Edouard. 2017. Philosophy within its proper bounds. Oxford: Oxford University Press.

18. Boorse, Christopher. 1975. On the distinction between disease and illness. Philosophy and Public Affairs 5: 49-68.

19. Parfit, Derek. 1984. Reasons and persons. Oxford: Oxford University Press.

20. Kauppinen, Antti. 2007. The rise and fall of experimental philosophy. Philosophical Explorations 10: 95-118.

21. Weinberg, Jonathan M., Chad Gonnerman, Cameron Buckner, and Joshua Alexander. 2010. Are philosophers expert intuiters? Philosophical Psychology 23: 331-355.

22. Egler, Miguel, and Lewis D. Ross. 2020. Philosophical expertise under the microscope. Synthese 197: 1077-1098.

23. Barnes, Elizabeth. 2016. The minority body: A theory of disability. Oxford: Oxford University Press.

24. Sytsma, Justin, Jonathan Livengood, Ryoji Sato, and Mineki Oguchi. 2015. Reference in the Land of the Rising Sun: A cross-cultural study on the reference of proper names. Review of Philosophy and Psychology 6: 213-230.

25. Robbins, Erin, Jason Shepard, and Philippe Rochat. 2017. Variations in judgments of intentional action and moral evaluation across eight cultures. Cognition 164: 22-30.

26. Greene, Joshua D., R. Brian Sommerville, Leigh E. Nystrom, John M. Darley, and Jonathan D. Cohen. 2001. An fMRI investigation of emotional engagement in moral judgment. Science 293: 2105-2108.

27. Nado, Jennifer. 2016. Advances in experimental philosophy and philosophical methodology. London: Bloomsbury.

28. Borry, Pascal, Paul Schotsmans, and Kris Dierickx. 2005. The birth of the empirical turn in bioethics. Bioethics 19: 49-71.

29. van Goidsenhoven, Leni, and Elisabeth de Schauwer. 2020. Listening beyond words: Swinging together. Scandinavian Journal of Disability Research 22: 330-339.

30. Faucher, Luc. 2012. Evolutionary psychiatry and nosology: Prospects and limitations. Baltic International Yearbook of Cognition, Logic and Communication 7: 5. https://doi.org/10.4148/biyclc. v7i0.1776. 
31. Wakefield, Jerome C., Kathleen J. Pottick, and Stuart A. Kirk. 2002. Should the DSM-IV diagnostic criteria for conduct disorder consider social context? American Journal of Psychiatry 159: 380-386.

32. Earp, Brian D., Joanna Demaree-Cotton, Michael Dunn, Vilius Dranseika, Jim A.C. Everett, Adam Feltz, Gail Geller, et al. 2020. Experimental philosophical bioethics. AJOB Empirical Bioethics 11: 30-33.

33. Earp, Brian D. 2019. Introducing bioXphi. The New Experimental Philosophy Blog, February 8, 2019. https://xphiblog.com/introducing-bioxphi.

34. Association for the Advancement of Philosophy and Psychiatry. 2020. Meetings and conferences. Accessed August 14, 2020. https://web.archive.org/web/20200814023652/https://philosophyandps ychiatry.org/meetings-conferences.

35. Earp, Brian D., Jonathan Lewis, Vilius Dranseika, and Ivar R. Hannikainen. 2021. Experimental philosophical bioethics and normative inference. Theoretical Medicine and Bioethics 42. https://doi. org/10.1007/s11017-021-09546-z.

36. Borg, Emma, Sarah A. Fisher, Nat Hansen, Richard Harrison, Deepak Ravindran, Tim Salomons, and Harriet Wilkinson. 2021. Pain priors, polyeidism, and predictive power: A preliminary investigation into individual differences in ordinary thought about pain. Theoretical Medicine and Bioethics 42. https://doi.org/10.1007/s11017-021-09552-1.

37. Linquist, Stefan, and Brady Fullerton. 2021. Transposon dynamics and the epigenetic switch hypothesis. Theoretical Medicine and Bioethics 42. https://doi.org/10.1007/s11017-021-09548-x.

38. Veit, Walter. 2021. Experimental philosophy of medicine and the concepts of health and disease. Theoretical Medicine and Bioethics 42. https://doi.org/10.1007/s11017-021-09550-3.

39. Smajdor, Anna. 2021. Why bother the public? A critique of Leslie Cannold's empirical research on ectogenesis. Theoretical Medicine and Bioethics 42. https://doi.org/10.1007/s11017-021-09549-w.

40. Cannold, Leslie. 1995. Women, ectogenesis and ethical theory. Journal of Applied Philosophy 12: $55-64$.

41. Alexander, Joshua, Ronald Mallon, and Jonathan M. Weinberg. 2010. Accentuate the negative. Review of Philosophy and Psychology 1: 297-314.

42. Ritchie, Stuart. 2020. Science fictions: Exposing fraud, bias, negligence and hype in science. London: Bodley Head.

43. Cova, Florian, Brent Strickland, Angela Abatista, Aurélien Allard, James Andow, Mario Attie, James Beebe, et al. 2021. Estimating the reproducibility of experimental philosophy. Review of Philosophy and Psychology 12: 9-44.

Publisher's Note Springer Nature remains neutral with regard to jurisdictional claims in published maps and institutional affiliations. 